\title{
LETTERS
}

\section{The authors respond to comments on the use of secure care in youth}

We thank Clark and colleagues ${ }^{1}$ for their presentation of an ethical perspective on secure care in response to our commentary on this topic, published in CMAJ. ${ }^{2}$ We fully agree that the ethical criteria presented in their letter ${ }^{3,4}$ are critical considerations in this important discussion. In our assessment outlined below, we conclude that secure care fails many of these fundamental ethical tests and is therefore ethically problematic on several fronts. Consistent with our commentary, ${ }^{2}$ this leads us to call for increased investments in voluntary treatment services and other supports, as opposed to secure care policies.

In describing the first ethical criterion for considering secure care, Clark and colleagues state, "If evidence does not support effectiveness of secure care in meeting treatment goals, such infringement on youth autonomy is ethically problematic." 1 Although secure care has not been specifically evaluated, there is an existing body of literature on the use of coercion in addiction treatment that raises substantial doubts about the expected ability of secure care to reduce negative outcomes among people who use drugs. ${ }^{5-7}$ Coercive interventions to treat addiction have been found to be inadequate in reducing negative substance use outcomes ${ }^{8}$ while increasing mental duress ${ }^{9}$ and risk of overdose. ${ }^{10}$ Given that secure care infringes on the autonomy of those it targets, it would seem to us that when deciding whether to proceed with this intervention, the "burden of proof" should be to show its effectiveness. As the existing evidence base does not show that coercion is effective in meeting its treatment goals, ${ }^{5-7}$ we conclude that secure care fails the "beneficence" test and is therefore ethically problematic on this front.

The second ethical criterion outlined by Clark and colleagues relates to interventions being "the least intrusive yet effective option ... it would be ethically problematic to design a system in which youth were routinely involuntarily placed in secure care when less restrictive approaches would likely be effective." ${ }^{1}$ Unfortunately, an abundance of evidence shows that the voluntary addiction treatment system in British Columbia is grossly inadequate. In a study of streetinvolved youth who use drugs in Vancouver, more than $25 \%$ of young people reported that they tried but were unable to access addiction treatment. ${ }^{11}$ After reviewing the addiction treatment system for young people in BC in 2016, the Office of the Representative for Children and Youth concluded that its review:

"reveals the absence of an actual 'system' with no single entity responsible for the planning and provision of services and no clear navigational path for youth and their families to follow. Across the health authorities in BC, substance use services for youth are piecemeal, with sometimes poorly resourced community-based services, and a shortage of withdrawal management and residential services for youth ... There are too few adequately resourced low-barrier community-based services to address youth needs before they become a crisis and too few treatment beds available when youth are ready to commit to residential treatment. In fact, there are only 24 publicly funded treatment beds in $\mathrm{BC}$, and, although the Ministry of Health is not able to say how many youth ages 13 to 18 meet the criteria for a substance use disorder (and there is no way of knowing how many of those youth will need residential treatment), we do know that about 68000 youth ages 15 to 24 meet [these] criteria - a clear indication that the 24 publicly funded treatment beds in $B C$ is a minuscule number."12

Given that the voluntary addiction treatment system in $\mathrm{BC}$ is inadequate and youth are known to face substantial barriers in accessing less intrusive treatment options, secure care would seem to fail the "autonomy" ethical test.

The third ethical criterion outlined by Clark and colleagues states that it is important that an "intervention does not cause greater harm than it seeks to prevent (nonmaleficence)." Although we agree that the intent of secure care is to prevent serious and catastrophic harms, including death, it is critical to recognize that secure care risks imposing unintended consequences that are equal to and, in our assessment, may exceed the negative outcomes it seeks to prevent. As described in our commentary, youth who are subjected to secure care and forced to abstain from substance use see decreased tolerance to illicit drugs, which drastically increases their risk of overdose upon discharge. ${ }^{2}$ Further, coercive approaches to substance use treatment risk undermining trust and our ability to connect youth who live with intergenerational, childhood or institutional trauma to the health and social services they need most. For these reasons, we see secure care failing the "nonmaleficence" ethical test.

An additional ethical criterion that Clark and colleagues describe relates to justice and the requirement that the intervention be fair. As noted in our commentary, secure care fails to acknowledge the underlying social determinants of health and root causes of substance use and risky practices. ${ }^{2}$ Additionally, it is our perspective that subjecting Indigenous youth to secure care suggests a colonial approach to addiction treatment that ignores the childhood, institutional and intergenerational trauma with which many Indigenous youth live. ${ }^{2}$ As such, it is our assessment that secure care fails the "justice" ethical test.

We reiterate our appreciation to Clark and colleagues for the ethical framework presented and contributions to this important dialogue on secure care. We equally agree that inaction on the overdose crisis is unacceptable and that swift action and adequate funding are needed. Given the ethical failings of secure care outlined above, it is our assessment that the priority must be to improve access to voluntary interventions, address the social determinants of health and consider how to build trusting relationships with youth who use drugs in order to meaningfully engage them in treatment and critical support services, including harm reduction interventions.

We similarly thank Warshawski and colleagues for their response to our commentary and for their efforts to respond to the devastation that the 
overdose crisis is having on young people, their families and our communities. ${ }^{13}$ We agree that urgent action is needed to address this emergency and that we have a duty to protect the health and wellbeing of young people who use drugs. We, however, respectfully disagree that secure care supports these objectives and maintain that it may result in more harm than good.

In considering the evidence base for secure care, Warshawski and colleagues suggest that clinicians and policy-makers review experiences from elsewhere in Canada. Unfortunately, the data they point to from Hull Services in Calgary are from internal monitoring and evaluation efforts, which may lack scientific rigour. Participant response rates are not reported and short- and long-term outcomes among clients - and, most importantly, risk of overdose upon release and long-term substance use patterns - are not included; nor were any data collection methods or outcomes subjected to the academic standards of peer review. ${ }^{13}$ As such, these data do not show that secure care is effective or safe. As noted in our discussion above, given that secure care infringes on the liberties and autonomy of people who use drugs, it is our assessment that the burden of proof should rest on establishing that the intervention is effective in meeting its objectives. Unfortunately, current evidence on secure care does not provide what we view as the necessary assurances that it can be expected to improve outcomes for young people.

We also respectfully disagree with Warshawski and colleagues that similar principles for the use of mandated care for youth with eating disorders should be applied to youth with substance use disorders. ${ }^{13}$ Although eating disorders and substance use disorders share some commonalities, the context of substance use is distinct and has critical implications for interventions and associated risks. Specifically, substance use takes place in a highly criminalized and stigmatized environment and the physiologic aspects of substance use (e.g., dependence, tolerance, withdrawal) are distinct. Stating that the same principles for intervening in the context of eating disorders should be applied to substance use fails to recognize the unique physiologic, sociostructural and environmental contexts of substance use and related harms, and is therefore ill informed and potentially dangerous.

Lastly, we acknowledge that although the former Representative for Children and Youth expressed support for the exploration of secure care in British Columbia, the subsequent and former Representative, Bernard Richard, cautioned against proceeding with secure care, stating, "before secure care is implemented, a significant weakness that has been identified in several [Representative for Children and Youth] reports must be addressed - that is, the current lack of a well-integrated and robust cross-ministerial network of supports and services for children and youth in BC." ${ }^{14}$ These sentiments are also shared by the current Representative for Children and Youth, Dr. Jennifer Charlesworth, who recently stated, "There is no compelling evidence to say that secure care achieves the outcomes we desire ... I'm not saying that there isn't a place for it, but I'm not in support of it until ... we have created a robust array of voluntary services and supports." 15

In conclusion, we continue to caution against the adoption of secure care measures. ${ }^{2}$ Instead, we call for increased accessible, evidence-driven interventions that include harm reduction, addiction treatment and trauma-informed recovery services, as well as efforts that build trust and meaningful connections with youth to support their engagement in critical health and social services.

\section{Kora DeBeck PhD}

Assistant professor, School of Public Policy, Simon Fraser University Research Scientist, BC Centre on Substance Use, Vancouver, BC

\section{Perry Kendall MD}

Clinical professor, School of Population and Public Health, University of British Columbia, Vancouver, BC; Former BC Provincial Medical Health Officer

\section{Danya Fast PhD}

Assistant professor, Department of Medicine, University of British Columbia Research Scientist, BC Centre on Substance Use, Vancouver, BC

\section{Andreas Pilarinos MPP}

PhD student, Interdisciplinary Studies Graduate Program, University of British Columbia; Research Assistant, BC Centre on Substance Use, Vancouver, BC

Cite as: CMAJ 2019 February 19;191: E199-200. doi: 10.1503/cmaj.71589

\section{References}

1. Clark BA, Preto N, Everett B, et al. An ethical perspective on the use of secure care for youth with severe substance use [letter]. CMAJ 2019;191:E195-6.

2. Pilarinos $A$, Kendall $P$, Fast $D$, et al. Secure care: more harm than good. CMAJ 2018;190:E1219-20.

3. Browne A, Blake M, Donnelly M, Herbert D. On liberty for the old. Can J Aging 2002;21:283-93.

4. Young JM, Everett B. When patients choose to live at risk: What is an ethical approach to intervention? BCMJ 2018;60:314-8.

5. Werb D, Kamarulzaman A, Meacham M, et al. The effectiveness of compulsory drug treatment: a systematic review. Int J Drug Policy 2016;28:1-9.

6. Lunze K, Idrisov B, Golichenko M, et al. Mandatory addiction treatment for people who use drugs: global health and human rights analysis. BMJ 2016;353: i2943.

7. Anderson JF. What to do about "much ado" about drug courts? Int J Drug Policy 2001;12:469-75.

8. Pasareanu AR, Vederhus J-K, Opsal A, et al. Improved drug-use patterns at 6 months postdischarge from inpatient substance use disorder treatment: results from compulsorily and voluntarily admitted patients. BMC Health Serv Res 2016;16:291.

9. Pasareanu AR, Vederhus J-K, Opsal A, et al. Mental distress following inpatient substance use treatment, modified by substance use; comparing voluntary and compulsory admissions. BMC Health Serv Res 2017;17:5.

10. Rafful C, Orozco R, Rangel G, et al. Increased nonfatal overdose risk associated with involuntary drug treatment in a longitudinal study with people who inject drugs. Addiction 2018;113:1056-63.

11. Phillips M, DeBeck K, Desjarlais T, et al. Inability to access addiction treatment among street-involved youth in a Canadian setting. Subst Use Misuse 2014;49:1233-40.

12. A review of youth substance use services in $B C$ May 2016. Victoria (BC): Representative for Children and Youth; 2016

13. Warshawski T, Charles G, Vo D, et al. Secure care can help youth reduce imminent risk of serious harm and prevent unnecessary death [letter]. CMAJ 2019;191:E197-8.

14. Representative's statement on Safe Care Act. Victoria (BC): Representative for Children and Youth; 2017.

15. Woo A. Young drug users should be involuntarily admitted into care, $\mathrm{BC}$ mom says. The Globe and Mail [Toronto] 2018 Nov. 25.

Competing interests: None declared. 